\title{
Da avaliação de um curso de especialização em docência na educação infantil à avaliação de uma Política Nacional de Formação Continuada
}

\author{
From an evaluation of a graduation course in early childhood \\ educationto to an analysis of a National Policy for Teacher Training
}

\section{Da evaluación de un curso de postgrado en Magisterio de Educación Infantil a la evaluación de una Política Nacional de Formación Docente}

\section{Angela Scalabrin Coutinho' Juliana Schumacker Lessa²}

\section{Resumo}

Este artigo aborda aspectosda política nacional de formação de professores da educação básica, mais especificamente da educação infantil, a partir de uma experiência de avaliação externa de um curso de especialização em docência em educação infantil. O objetivo é problematizar a proposição de uma política nacional de formação de professores, tomando por base duas categorias: relação teoria e prática e condições de frequência e permanência na formação. Tais categorias são provenientes da análise dos discursos obtidos mediante questionários de avaliação das disciplinas do referido curso de especialização e do acompanhamento de atividades desenvolvidas no curso como seminários e defesas de trabalhos de conclusão de curso. Identificou-se, a partir da análise crítica de discurso, a importância de um curso que tenha a práxis como mote de orientação da formação e a ampliação da ideia de regime de colaboração entre os entes federados para além do financiamento parcial de processos formativos, sendo necessário incluir condições mais amplas de frequência aos cursos e políticas de continuidade no contexto local.

Palavras-chave: Política de Formação. Formação de Professores. Especialização em Docência na Educação Infantil. Análise Crítica de Discurso.

\footnotetext{
1 Doutora em Eduação. Professora no curso de Pedagogia na Universidade Federal do Paraná e Pesquisadora do Núcleo de Estudos e Pesquisa em Infância e Educação Infantil (NEPIE/UFPR) e do Núcleo de Estudos e Pesquisas da Educação da Pequena Infância (NUPEIN/UFSC). E-mail: angelamscoutinho@ gmail.com

2 Doutoranda do Programa de Pós-Graduação em Educação da Universidade Federal de Santa Catarina. Graduada em Pedagogia (2008) e Mestre em Educação (2011) pela mesma instituição. Pesquisadora do Núcleo de Estudos e Pesquisas da Educação da Pequena Infância (NUPEIN/UFSC). E-mail: julianallessa@gmail.com
} 


\begin{abstract}
This article focuses on the components of the national policy for teacher training in elementary education, more specifically in early childhood education, as seen through the experience of assessing a specialization course (lato sensu) for teachers in early childhood education. Its main objective is to problematize the proposal of a national policy for teacher education, taking two main categories as its basis: the relationships that takes on theory and practice, and conditions that are based on attendance and stay during the education process. Such categories are from the analysis of students' discourses that were obtained with discipline assessment questionnaires applied in the referred course, and from the follow-up activities undertaken, such as seminars and the students' final paper viva. By using the Critical Discourse Analysis theoretical framework, it was possible to identify the importance of a course that presents the praxis as its guiding motto in teacher education, and the development of a collaborative regime among federal agencies that goes beyond partial funding for education processes. It is also necessary to include broader frequency requirements to courses such as these, and training policies in the local context.
\end{abstract}

Key-words: Education policy; Teacher Education; Specialization in teaching for early childhood education; Critical Discourse Analysis.

\title{
Resumen
}

En este artículo se discute aspectos de la política nacional de formacíon de maestros para la educación básica, especialmente para la educación de la primera infancia desde una experiencia de evaluación externa de un curso de especialización en la enseñanza en la educación infantil. La intención es discutir la propuesta de una política nacional para la formación del profesorado, basado en dos categorías: la teoría y la práctica y la relación de condiciones de frecuencia y permanencia en la formación. Estas categorías se derivan del análisis de los discursos obtenidos a través de cuestionarios de evaluación de los sujetos de ese curso de especialización y las actividades complementarias llevadas a cabo en el curso de seminarios y defensas de la finalización del trabajo de curso. Se identificó a partir del análisis crítico del discurso, la importancia de un curso que tiene la praxis como un lema de entrenamiento de orientación y la expansión de la idea de colaboración entre las entidades federales más allá de la financiación parcial de los procesos de formación, sendo necesario incluir condiciones más amplias de la asistencia a cursos y políticas de continuidad en el contexto local.

Palabras-clave: Política de Formación Docente; Formación de Maestros; Especialización en Docencia en la Educación Infantil; Analisis Crítica del Discurso. 


\section{Introdução}

Este artigo tem como intenção apresentar algumas reflexões resultantes de um processo de avaliação educacional no plano de uma política de formação. Trataremos, particularmente dos dados obtidos com a realização de uma pesquisa de avaliação externa junto ao Curso de Especialização em Docência na Educação Infantil (CEDEI), durante o período de 2012 a 2014. O Curso, com carga horária de 360 horas, na modalidade presencial, foi ofertado pela Universidade Federal de Santa Catarina, no âmbito do Centro de Ciências da Educação, e coordenado pelo Núcleo de Desenvolvimento Infantil.

Ofertado em convênio com o Ministério da Educação (MEC), via Secretaria de Educação Básica (SEB), em articulação com as Instituições Federais de Ensino Superior (IFE's), com a União Nacional dos Dirigentes Municipais de Educação (UNDIME) e as Secretarias Municipais de Educação (SME's), a Especialização em Docência na Educação Infantil se situa no contexto de uma Política Nacional de Formação de Profissionais do Magistério da Educação Básica. Instituída no ano de 2009, por meio do Decreto Presidencial n 6.755, a Política Nacional de Formação ampara-se, fundamentalmente, na Constituição, na Lei de Diretrizes e Bases da Educação Nacional (LDB), no Plano Nacional de Educação e na Lei que institui a Coordenação de Aperfeiçoamento de Pessoal de Ensino Superior (CAPES) como fundação pública, prevendo suas funções.

O amparo na Constituição se dá no que diz respeito à responsabilidade da União de organizar o sistema federal de ensino, financiando as instituições de ensino públicas federais e exercendo em matéria educacional, "função redistributiva e supletiva, de forma a garantir equalização de oportunidades educacionais e padrão mínimo de qualidade do ensino mediante assistência técnica e financeira aos Estados, ao Distrito Federal e aos Municípios" (BRASIL, 1988, Art. 211). A Política se ampara na LDB, mais precisamente quando esta Lei institui que o ensino deve ser ministrado com base nos princípios de "valorização do profissional da educação escolar" e na "garantia de padrão de qualidade" e ainda, que os sistemas de ensino devem ser organizados em regime de colaboração entre a União, os Estados, o Distrito Federal e os Municípios (LDB, 1996, Art. $3^{\circ}$, Art. $8^{\circ}$ ).

A partir desses pressupostos, a Política Nacional de Formação de Profissionais do Magistério da Educação Básica tem como finalidade: "organizar, em regime de colaboração entre a União, os Estados, o Distrito Federal e os Municípios, a formação inicial e continuada dos profissionais do magistério das redes públicas de educação básica" (BRASIL, 2009a, Art. 1).

Entre os princípios da Política Nacional, a formação docente em todos os níveis da educação básica é concebida como compromisso público de Estado, o qual assegura os direitos das crianças, jovens e adultos à educação de qualidade, compromisso este assinalado como um projeto social, político e ético que contribui "para a consolidação de uma nação soberana, democrática, justa, inclusiva e que promova a emancipação dos indivíduos e grupos sociais" (BRASIL, 2009a, Art. $2^{\circ}$ - I e II). Outros princípios que sustentam a Política Nacional de Formação referem-se à importância atribuída à valorização profissional docente, traduzida em políticas permanentes de estímulo à profissionalização, à formação continuada, progressão na carreira, dedicação exclusiva ao magistério e melhoria nas condições de remuneração e de trabalho. Mais especificamente em relação à formação continuada, a Política Nacional parte do princípio que de esta formação é componente essencial da profissionalização docente, sendo reconhecidos os professores como agentes formativos de cultura que, como tal, têm necessidade permanente de acesso a informações, vivências e atualizações culturais (BRASIL, 2009a, Art. $2^{\circ}-\mathrm{XI}$, XII).

Dentre os objetivos da Política, ocupa lugar central a oferta e a expansão de cursos de formação inicial e continuada a profissionais do magistério, pelas instituições públicas de ensino superior. O cumprimento deste, dentre outros objetivos deve ser feito por meio de ações e programas específicos do Ministério da Educação, fomentados pela Coordenação de Aperfeiçoamento de Pessoal de Nível Superior (CAPES). Dentre essas ações, o atendimento às necessidades de formação continuada de profissionais do magistério está previsto para 
acontecer por meio de cursos presenciais ou à distância, realizados a partir da articulação entre o Ministério da Educação, as instituições de ensino superior formadoras e os sistemas e redes de ensino municipais. O apoio do Ministério da Educação às ações de formação continuada (e inicial também) é feito mediante a concessão de bolsas de estudo e bolsas de pesquisa para professores, e apoio financeiro aos Estados, Distrito Federal, Municípios e às instituições de educação superior selecionadas para participar da implementação de programas, projetos e cursos de formação inicial e continuada.

Se formos analisar a configuração em que se encontram as ações instituídas pela Política Nacional de Formação, a saber, ações de formação inicial e continuada, veremos que estas fazem parte de um enredo de metas e ações, previstas no Plano de Desenvolvimento da Educação (PDE), em vigor desde abril de 2007. Nele, os programas de ação foram organizados em quatro principais eixos: a educação básica, a educação superior, a educação profissional e a alfabetização. No interior do eixo educação básica, o programa tem como ação a formação de professores, bem como o piso salarial nacional:

Um dos principais pontos do PDE é a formação de professores e a valorização dos profissionais da educação. A questão é urgente, estratégica e reclama resposta nacional. Nesse sentido, o PDE promove o desdobramento de iniciativas fulcrais levadas a termo recentemente, quais sejam: a distinção dada aos profissionais da educação, única categoria profissional com piso salarial nacional constitucionalmente assegurado, e o comprometimento definitivo e determinante da União com a formação de professores para os sistemas públicos de educação básica (PDE, 2007, p. 16).

Nessa política educacional, portanto, é que cabe situar a proposta da Especialização em Docência na Educação Infantil, ou seja, compondo uma das ações de uma Política Nacional de Formação que visa a valorização docente e a qualificação da educação. Tal intento é identificado nos três eixos de formação que estruturaram o curso, como veremos, em uma visível compreensão da formação a partir da práxis:

I. Fundamentos da educação infantil (concepção de infância e de criança, direitos da criança, políticas públicas de educação infantil, concepção de desenvolvimento e aprendizagem, atividades principais);

II. Identidades, práticas docentes e pesquisa (metodologia de pesquisa com crianças, reflexões críticas sobre a prática pedagógica, relação teoria e prática);

III. Cotidiano e ação pedagógica (currículo, proposta pedagógica, planejamento, tempo e espaço, corpo e movimento, brinquedos e brincadeiras, linguagem, oralidade, literatura e letramento, arte, expressão, música, natureza, ciências e matemática na educação infantil).

\section{Os percursos para se chegar a uma avaliação}

Nesse artigo o foco da discussão se dará em torno de duas categorias de análise, as quais chegamos durante o processo de realização de uma avaliação educacional externa. As categorias foram construídas a partir da análise das respostas dadas pelas discentes, registradas em questionários, estes, preenchidos conforme a disciplina e após a realização de cada uma delas ${ }^{3}$. O questionário, utilizado para as doze disciplinas do curso, entregues ao corpo discente de cada um dos polos (Araranguá e Florianópolis), consistiu num dos instrumentos metodológicos utilizados na avaliação, juntamente com a participação e registro das reuniões (de colegiado, de professores e restritas da coordenação), e defesas de trabalhos de conclusão de curso. Ainda que as reflexões sejam resultantes da somatória desses recursos, que permitiu uma visão do contexto global do curso, participando também de suas questões pedagógicas mais específicas, a análise das respostas coletadas por meio dos questionários, sem sombra de dúvidas, foi o instrumento que permitiu chegarmos a um volume denso de dados, os quais foram transcritos em planilhas. Dos 780 questionários entregues, obtivemos uma devolutiva de 280, perfazendo uma amostra analisada de 36\% de questionários discentes (64\% não retornaram). Embora

3 As disciplinas do curso foram cursadas uma a uma, portanto, ao final de cada disciplina fora entregue um questionário para que fosse avaliada a disciplina, em relação a três eixos, os quais falaremos mais adiante. 
o retorno em um dos polos tenha sido bastante baixo, salientamos que a amostra é significativa, pois o total de questionários analisados representa um pouco mais de um terço do total de participantes. Para a organização dos dados optamos pela construção de uma pasta de planilhas, formada pelo conjunto de planilhas contendo as respostas das acadêmicas para cada item do questionário, por disciplinas e por polos.

Esta organização, resultante de um trabalho extenso e intenso de transcrição permitiu a leitura atenta a todas as respostas e a visualização destas no seu conjunto, sendo posteriormente analisadas a luz do método de análise de discurso, no sentido de identificar aspectos relevantes para uma análise situada.

Neste aspecto, buscamos a compreensão a partir da "análise crítica de discurso", definida por Fairclough (2001, p. 91), em que o discurso é em si uma ação social, sendo tanto moldado como alterado pela estrutura social, portanto, o discurso não é individual, mas socialmente situado: "o discurso contribui para construção de identidades sociais, para a construção de relações sociais entre as pessoas e para a construção de sistemas de conhecimentos e crenças". Considerando as orientações de Fairclough (2001), para além da seleção dos aspectos mais recorrentes ou ausentes, o processo analítico das respostas dos questionários se deu de modo a colocar em confronto os discursos com os objetivos do curso, com o perfil das profissionais e a constituição da área da educação infantil, aspectos que se revelaram como categorias relevantes para elaborar a avaliação do curso desenvolvida e outras propostas de formação.

Como a estruturação dos discursos depende das condições sociais para tal, pensamos ser importante sublinhar aqui que a recolha das vozes das profissionais em formação se iniciou quando o curso já estava em andamento, deste modo, questionários relativos a algumas disciplinas foram respondidos algum tempo depois de sua conclusão. Soma-se a esta condição, o fato de o questionário ser relativamente longo, o que consideramos afetou a disponibilidade para respondê-lo.

Os eixos que orientaram as questões construídas para integrar o questionário foram: I. Conteúdo da Disciplina; II. Estrutura da Disciplina; III. Participação na Disciplina e Condições; IV. Aspectos Gerais. O conjunto de questões dos três primeiros eixos relacionava-se, mais especificamente, à disciplina comportando, portanto, dados mais singulares relativos a cada disciplina, o último eixo foi formado por questões em relação ao curso como um todo.

Compõem o quadro de sujeitos desta avaliação as 46 profissionais ${ }^{4}$ que concluíram o curso, o que corresponde a $52 \%$ dentre as matrículas realizadas $(88)^{5}$. Este dado é relevante, pois isso significa que o curso teve uma taxa de desistência em torno de 48\%, correspondendo a 42 profissionais que, apesar de matriculadas, não concluíram o curso ${ }^{6}$. Este percentual se aproxima da metade das matrículas realizadas, o que gera um conjunto de questões ${ }^{7}$ acerca das razões que levam um número tão elevado de profissionais a não concluírem o curso. A análise desses dados percorre uma reflexão em torno das condições de frequência e permanência no curso, esta, portanto, que consistiu numa das categorias de análise da avaliação. Uma segunda categoria buscou abarcar um conjunto de reflexões em torno da relação teoria e prática na formação. A seguir apresentamos as discussões mobilizadas em torno dessas categorias e, por fim realizamos uma análise crítica acerca do curso no bojo de uma Política Nacional de Formação dos/as Profissionais da Educação Básica.

4 Utilizaremos a denominação profissionais no feminino, tendo em vista que o corpo discente era formado por $92 \%$ do sexo feminino. A partir dos dados fornecidos pela coordenaçã̃o do curso, pudemos verificar se tratar de mulheres atuantes na educação infantil $(96 \%)$, na função de docência (82\% atuam diretamente com as crianças), com uma carreira relativamente recente na área ( $45 \%$ delas atuam há menos de 5 anos na área), com idade entre $21 \mathrm{e}$ 40 anos (80\%) (Cf. CEDEl, 2014).

5 Esta quantidade de matrículas (88) foi dividida em duas turmas, localizadas geograficamente em dois polos: um na cidade de Araranguá e outro na cidade de Florianópolis, ambas situadas no Estado de Santa Catarina.

6 Essa desistência ocorreu em alguns casosao longo da realização das disciplinas, ou no momento da realização ou entrega do trabalho final de conclusão do curso.

7 Esse dado mobilizou a coordenação do curso a realizar uma pesquisa sobre gênero, condições de trabalho e carreira com as profissionais participantes do CEDEI. 


\section{No confronto das avaliações: olhares sobre o curso}

Nesta seção analisaremos as categorias delimitadas por eixos a partir dos discursos das profissionais em formação. Alertamos, a partir das palavras de Fairclought (2001, p. 173), que "é importante levar em consideração as formas pelas quais os intérpretes interpretam os textos, para que se possa avaliar adequadamente a sua eficácia política e ideológica".

Esse alerta se justifica por alguns motivos que passamos a explicitar. O primeiro está na base da própria concepção de avaliação que orienta o nosso olhar para os discursos, pois partimos da ideia que:

[...] iniciar um processo de avaliação implica uma clareza sobre os objetivos que deve ser alcançada pela cooperação de todos os atores sociais que nele podem estar envolvidos. Pode-se avaliar para realizar um ato de autoridade e reafirmar uma posição de poder; pode-se avaliar para tomar decisões sensatas; pode-se avaliar para refletir sobre o que foi realizado com a finalidade de formular hipóteses de melhorias (BONDIOLI, 2004, p. 144)

Inspiradas na problematização elaborada por Bondioli, encaminhamos o processo de avaliação do curso atentando para o objetivo de refletir sobre o que foi realizado, com o intuito de formular hipóteses de melhoria, bem como historicizar essa experiência específica de formação, incluindo os principais atores: as profissionais da educação infantil em formação. Contudo, é fato que os dados selecionados para uma análise mais aprofundada partem da uma leitura política e ideológica acerca dos processos de formação de professores, já que o foco do curso é a docência, assim como as bases da educação infantil.

Esses dois aspectos, concepção de formação e de educação infantil, delimitam os demais motivos que delineiam as formas para a interpretação dos discursos. Importante demarcar esses eixos balizadores, por que eles determinam as categorias aqui delimitadas.

Destacamos também que essa interpretação dos discursos ocorreu desde o momento que recebemos os primeiros questionários, tendo em vista que a sua leitura já nos permitia, ainda que de modo parcial, demarcar algumas características do curso. Esse movimento constante de análise nos permitiu fazer pequenas sínteses junto à equipe de coordenação, que ao longo do curso retomou alguns elementos situados pelas profissionais em formação, no sentido de repensar o curso no processo de desenvolvimento.

As categorias aqui delimitadas nos permitem considerar as vozes das profissionais que participaram do curso, ponderar algumas questões para planejamento de cursos posteriores, bem como problematizar as políticas de formação de professores da educação infantil.

\section{Relação teoria e prática}

Há, nos discursos das profissionais em formação, uma clara defesa por uma perspectiva de formação que não dissocie a teoria e a prática. Santos (2014, p. 126), ao analisar as avaliações de processos de formação continuada para a educação infantil na rede municipal de ensino de Florianópolis entre os anos de 2005 a 2012 , identificou esse mesmo posicionamento, salientando que, por vezes, "as profissionais dão ao termo teoria um sentido de oposição ao de prática, como desnecessária, excessiva e cansativa”.

Para analisar tal posicionamento, a pesquisadora se apoia na defesa de Ghedin (2002, p. 138) ao pontuar que:

Teoria e prática são processos indissociáveis. Separálos é arriscar demasiadamente a perda da própria possibilidade de reflexão e compreensão. A separação de teoria e prática se constitui na negação da identidade humana. Quando se executa tal movimento permitese 0 retorno à negação do ser, isto é, ao se negar a indissociabilidade entre prática e teoria, negase, em seu interior, aquilo que tornou 0 ser humano possível: a reflexão instaurada pela pergunta. A alienação encontrase justamente na separação e dissociação entre teoria e prática (apud SANTOS, 2014, p. 120)

Pela pesquisa de Santos (2014, p. 90) temos a apresentação de uma importante contribuição de Ghedin, ao afirmar que a formação de professores requer a mudança de uma epistemologia da prática para uma epistemologia da práxis. Isso porque, teoria e prática são dimensões de um mesmo processo, que implica a ação e reflexão, com base num processo de teorização. 
No discurso das profissionais em formação do CEDEI, foi possível perceber que quando as disciplinas tendem para uma dimensão ou outra, as profissionais posicionaram-se contrárias, indicando que essa "divisão" não é interessante e nem relevante para a formação, como mostra uma fala sobre as contribuições de uma disciplina e uma sobre a adequação dos seus objetivos:

Algumas vezes sim, quando (...) inicia um diálogo sobre sua prática, mas se distanciou muito da apostila, pouco a utilizamos (A08).

(...) voltados para a prática, enquanto eu gostaria de refletir a prática com a teoria (A10).

A apostila a que se refere a discente trata-se de uma compilação de textos e referências bibliográficas, previamente selecionados pelos/as docentes das disciplinas. Embora a leitura e discussão dos textos não assegurem a dimensão da teorização, é possível identificar, no conjunto de falas das profissionais, que o fato de não haver discussões a partir do referencial teórico indicado para a disciplina, tornou a sua abordagem restrita ao âmbito da experiência direta, ou seja, da prática.

Na segunda fala identificamos a percepção crítica da profissional, ao avaliar que os objetivos da disciplina se focaram na prática, quando na verdade, na sua análise, o foco deveria ter sido a análise da prática, com base na teoria. A perspectiva indicada pela discente, ou seja, a de que partindo da prática, da sua constituição para, à luz da teoria, problematizá-la, não desconsidera a característica dialética própria da relação teoria e prática, já que "[...] caberia observar que teoria e prática são momentos de um mesmo processo" (SAVIANI, 2005, p. 18).

Partir da prática torna-se o caminho mais óbvio para as profissionais, porque esse é o seu ponto de referência, até porque para frequentar esse curso era necessário que estivessem atuando diretamente na educação. No entanto, os posicionamentos de crítica de que uma perspectiva focada na prática por si só não permite a qualificação do processo de formação, dá visibilidade à compreensão das profissionais sobre a necessária mudança dos processos de formação de uma epistemologia da prática para uma epistemologia da práxis, como defende Ghedin (2002).

Podemos também ressaltar o que aponta Nóvoa (1992, p. 28), de que é preciso investir positivamente nos saberes de que o professor é portador, porém trabalhando-os de um ponto de vista teórico e conceitual:

Ora é forçoso reconhecer que a profissionalização do saber na área das Ciências da Educação tem contribuído para desvalorizar os saberes experienciais e as práticas dos professores. A pedagogia científica tende a legitimar a razão instrumental: os esforços de racionalização do ensino não se concretizam a partir de uma valorização dos saberes de que os professores são portadores, mas sim através de um esforço para impor novos saberes ditos «científicos». A lógica da racionalidade técnica opõe-se sempre ao desenvolvimento de uma práxis reflexiva.É preciso trabalhar no sentido da diversificação dos modelos e das práticas de formação, instituindo novas relações dos professores com o saber pedagógico e cientííico.

Abaixo seguem outras respostas, elaboradas pelas discentes, e que foram aqui selecionadas dentre as inúmeras transcritas, pois seu teor crítico nos ajuda a ressaltar que o confronto entre a teoria e a prática é fundamental para o processo formativo:

Foi uma disciplina que envolveu muito nossa prática, trazendo a ligação da teoria com a prática (A02).

0 aprofundamento das visões teóricas, das concepções de infância pelo olhar de diversos autores fazendo contrapontos com a atualidade, foi bastante rico (A08).

Ao tratar da clareza da abordagem do tema pelos/as docentes responsáveis pela disciplina, uma das profissionais respondeu:

Sim, a professora conseguiu fazer links importantes entre a teoria e a prática. Foi clara na explicação de todos os conceitos apresentados na disciplina (A08).

Cabe salientar que embora esse posicionamento seja majoritário no conjunto de respostas, há discursos que questionam as disciplinas que não deram ênfase à prática:

Muito pouco; (...), esperava mais para a prática (A08). 
A partir dos excertos apresentados e outros que se somam a estes foi possível observar que a relação teoria e prática, além de ser um eixo importante do curso, merece destaque enquanto tema da formação, pois problematizar junto às profissionais o caráter dessa relação permite também significá-la, algo fundamental para a constituição de uma práxis.

É preciso que os professores possam se assumir como produtores da "sua" profissão e de acordo com Nóvoa (1992, p. 29):

A formação passa por processos de investigação, directamente articulados com as práticas educativas. A dinamização de dispositivos de investigação-acção e de investigação-formação pode dar corpo à apropriação pelos professores dos saberes que são chamados a mobilizar no exercício da sua profissão. A este propósito é útil conjugar uma formação de tipo clínico, isto é baseada na articulação entre a prática e a reflexão sobre a prática (Perrenoud, 1991), e uma formação de tipo investigativo, que confronte os professores com a produção de saberes pertinentes (Elliott, 1990). 0 esforço de formação passa sempre pela mobilização de vários tipos de saber: saberes de uma prática reflexiva; saberes de uma teoria especializada; saberes de uma militância pedagógica (Hameline, 1991).

A densidade da proposição de Nóvoa remete para uma perspectiva formativa que projeta e articula formação inicial e continuada, investigação, prática pedagógica, conhecimentos pertinentes e a dimensão política, portanto, uma formação que privilegia a práxis.

\section{Condições de frequência}

Como já explicitado na introdução deste artigo o CEDEl faz parte de uma Política Nacional de Formação, integrando um conjunto de ações que articulam a necessária colaboração entre os diferentes entes federados. Trata-se, assim, de um programa de formação que expressa o compartilhamento de interesses e responsabilidades entre o Governo Federal e os Municípios (no que se refere, sobretudo, à educação infantil). Lembremos aqui, uma vez mais esta nossa afirmação, presente no Decreto Presidencial n 6.755, de 2009:

Fica instituída a Política Nacional de Formação de Profissionais do Magistério da Educação Básica, com a finalidade de organizar, em regime de colaboração entre a União, os Estados, o Distrito Federal e os Municípios, a formação inicial e continuada dos profissionais do magistério para as redes públicas da educação básica (BRASIL, 2009a, Art. $1^{\circ}$ ).

Tendo em vista o grande investimento realizado pelo Governo Federal, a mobilização e envolvimento das Universidades nesse processo, desde a gestão interna do recurso, à organização de espaço físico, corpo docente, certificação, fica compreendido que o aproveitamento do curso com qualidade deveria ser assegurado a todas as profissionais em formação.

No entanto, o que observamos é que a frequência com condições de pleno aproveitamento precisaria ser garantida pelos Municípios e seus respectivos sistemas de ensino às profissionais. Isso implica não só disponibilidade de tempo para a presença nas aulas, quando o curso ocorre em período diurno e semanal ${ }^{8}$, mas também tempo de estudo na sua jornada de trabalho, afinal o CEDEl configura-se como formação continuada em nível de pós-graduação.

Nessa via de reflexão, os discursos das profissionais revelam dados importantes:

Sair em um dia de trabalho para estudar para "muitos" é tarefa complicada. Sendo pois que a formação continuada é um direito (A01).

Sou uma boa aluna e procuro me dedicar ao máximo, porém como atuo 40h em sala de aula não consegui realizar todas as leituras com antecedência, então algumas foram realizadas posteriormente (A08).

Em algumas falas foi possível identificar ainda, além da falta de tempo para frequência e estudo, o fato de terem que pagar alguém para ficar em seu lugar enquanto estavam em um espaço-tempo de formação. Esses aspectos revelam que apesar da formação continuada ser um direito dos professores - desde a Lei de Diretrizes e Bases da Educação Nacional (1996) e mais atualmente pela Política Nacional de Formação (Decreto Presidencial $\left(n^{\circ}\right.$ 6.755/2009) que define que essa formação deve acontecer por meio da oferta de cursos por instituições públicas

8 Como foi o caso no polo de Araranguá em que houveram aulas no período da sexta feira pela tarde. 
de educação em consonância com os projetos das redes de ensino -, essa formação ainda se efetiva sustentada por esforços individuais e não por políticas de formação articuladas. O esforço individual entrelaça-se nos princípios perversos de favor/compensação e meritocracia, ou seja, por um lado favor aos sistemas municipais de ensino (quando as professoras são liberadas, mas precisam "pagar" quem as substituirá) e, por outro, a meritocracia, o esforço de quem enfrentou dificuldades, mas conseguiu. Estes aspectos, que estamos denominando de princípios perversos alimentam a engrenagem de precarização do trabalho docente, como afirma Freitas (2012, p. 96):

As condições perversas que contribuem para a degradação de uma profissão - a baixa qualidade da formação e a ausência das condições adequadas ao trabalho entre as quais se inclui a baixa remuneração, a ausência da carreira com jornadas adequadas

ao aprimoramento profissional constante - estão presentes em nossas escolas públicas há décadas, degradando 0 exercício da profissão docente (grifos nossos).

O uso do termo "perversas" revela o paradoxo que se torna para as profissionais a adesão a um processo de formação que, ao mesmo tempo em que promove o seu desenvolvimento profissional, resulta numa sobrecarga de trabalho, tendo que recorrer a acordos internos nas instituições, muitas vezes, acordos sugeridos pelas próprias gestões. Essas dificuldades ficam evidentes quando consideramos os índices de evasão que, no caso dessa edição do curso foi de $60 \%$ no polo de Araranguá e $40 \%$ no polo de Florianópolis. Embora saibamos que esse dado implica um amplo conjunto de interferentes, como a própria organização da vida pessoal, o fato da maioria ser mulher, da exigência de uma disciplina de estudo própria de cursos de pós-graduação e, principalmente, daqueles que ofertam as disciplinas de forma intensiva, não há dúvidas de que as condições de trabalho interferem de modo proeminente na desistência das profissionais em formação.

Outro aspecto importante a ser destacado é a necessidade de condições na própria estrutura do curso, pois uma indicação constante das profissionais que frequentavam o curso no polo de Araranguá era a ausência de uma biblioteca para que pudessem aprofundar seus estudos, sobretudo, no período de elaboração do trabalho de conclusão do curso. Este aspecto extremamente limitador da formação se coloca como ponto de grande importância a ser considerado na medida em que há a intenção de ampliar o campo de atuação da Política Nacional de Formação. Neste sentido, é legítima a preocupação em ofertar cursos que extrapolem contextos próximos aos grandes centros urbanos - os quais geralmente contam com estrutura mais ampla de Universidades, bibliotecas e demais espaços e materiais de estudo e formação -, para contextos que estão à margem e possuem uma clara demanda por formação, porém, a resposta apenas sob o viés da oferta não é suficiente.

\section{Da avaliação de um Curso de Especialização em Docência na Educação Infantil à avaliação de uma Política Nacional de Formação Continuada}

Inserido no bojo de uma Política Nacional de Formação Continuada, o Curso de Especialização em Docência na Educação Infantil, dentre os cursos previstos pelo Ministério da Educação para esta etapa educacional é, sem dúvidas, o seu "carro-chefe". Nesse sentido, uma ampla avaliação do seu desenvolvimento é importante, não só para as edições propostas em Santa Catarina, mas para a proposição de uma política de formação que induza outras ações dos municípios e instituições que atuam junto à educação infantil.

No que tange ao regime de colaboração entre os diferentes entes, anunciado na Política Nacional de Formação, o CEDEl é uma ação que efetiva em parte tal pressuposto, anunciado desde a LDB 9394/96, já que coloca em relação direta a articulada o âmbito federal e municipal, além do que responsabiliza o governo federal pelo financiamento da formação continuada por meio de curso de pós-graduação latu senso. Freitas (2012, p. 97) ressalta algumas dificuldades dessa articulação:

As dificuldades nesse processo se devem, sobretudo nas condições atuais, ao caráter federativo de nosso país e a autonomia dos entes federados, condicionantes importantes na determinação dos atuais desenhos das políticas docentes, que possibilitam a construção de políticas nos territórios dos estados, mas também contraditoriamente impeditivas de ações mais articuladas e orgânicas entre união, estados e municípios, que poderiam nos fazer avançar na superação das condições perversas produzidas pelas políticas neoliberais que herdamos do século passado. 
Como vimos, a proposta do curso busca atender a algumas orientações e determinações legais. No âmbito das orientações cabe citar o Parecer do Conselho Nacional de Educação $n^{\circ} 20$, de 2009, que subsidiou a Revisão das Diretrizes Curriculares Nacionais para a Educação Infantil:

Programas de formação continuada dos professores e demais profissionais também integram a lista de requisitos básicos para uma Educação Infantil de qualidade. Tais programas são um direito das professoras e professores no sentido de aprimorar sua prática e desenvolver a si e a sua identidade profissional no exercício de seu trabalho (BRASIL, 2009c, p. 13)

No campo das determinações, o Decreto Presidencial que institui a Política Nacional de Formação de Profissionais do Magistério da Educação Básica ( $n^{\circ}$ 6.755/09), detalha quais princípios da política de formação devem ser assegurados, os quais alguns foram apresentados na introdução deste trabalho e outros damos ênfase aqui, por considerarmos pertinentes após a discussão que viemos percorrendo:

- a articulação entre a teoria e a prática no processo de formação docente, fundada no domínio de conhecimentos científicos e didáticos, contemplando a indissociabilidade entre ensino, pesquisa e extensão;

- a importância do projeto formativo nas instituições de ensino superior que reflita a especificidade da formação docente, assegurando organicidade ao trabalho das diferentes unidades que concorrem para essa formação e garantindo sólida base teórica e interdisciplinar (BRASIL, 2009a, Art. $2^{0}$ - V, VII).

Ainda que o CEDEl se constitua como importante ação no sentido da busca pela superação da desarticulação histórica entre os entes federados, conforme foi possível constatar acerca das condições de frequência e permanência no curso, fica evidente que um regime de colaboração apenas no âmbito do financiamento não é suficiente. Há ainda a necessidade de uma normativa que tenha maior poder de alcance no que se refere a uma articulação efetiva, que permita que, de fato, as profissionais usufruam do direito à formação e assegure as condições para tal. Nesse sentido, a avaliação do curso, realizada no âmbito de uma política educacional nos permite indicar a necessidade de algumas condições ainda a serem asseguradas, sobretudo por parte dos municípios e suas redes de ensino, no que se refere à participação das profissionais em cursos como este. Cabe aqui pontuar que o direito a 33\% de hora-atividade já é reconhecido em Lei. Este indicativo resulta, principalmente, da análise realizada sobre a sobrecarga de tarefas das discentes, lembremos, profissionais em formação, que, com a realização do curso, passam a conjugar com seu trabalho, os estudos noturnos e aos finais de semana. É importante ressaltar ainda, nessa soma de tarefas, aquelas relacionadas ao âmbito doméstico, em que muitas mulheres, como sabemos, ainda são as únicas responsáveis. Todos esses fatores, podemos dizer dificultam (quando não, impedem) o aproveitamento e até a permanência no curso.

Coaduna-se com Nóvoa (1992, p. 30) quando afirma que:

a formação de professores deve ser concebida como uma das componentes da mudança, em conexão estreita com outros sectores e áreas de intervenção, e não como uma espécie de condição prévia da mudança. A formação não se faz antes da mudança, faz-se durante, produz-se nesse esforço de inovação e de procura dos melhores percursos para a transformação da escola.

Embora se conceba que as próprias profissionais serão protagonistas da mudança, no sentido de questionar e instaurar o debate constante e sistemático sobre o que é ser professora na educação infantil, este deve fazerse presente durante o processo de formação, considerando-se a situação privilegiada de estudos, debates e sínteses, o que depende de políticas efetivas de formação profissional que não dependam exclusivamente do esforço pessoal de cada um.

\section{Em tom de conclusão}

A experiência de avaliação do CEDEI revelou a complexidade que envolve os processos de formação de professores, tendo em vista questões epistemológicas, teóricas e estruturais. Por outro lado, a proposição e o desenvolvimento de um curso de formação desta natureza também dão indicativos das possibilidades do regime 
de colaboração entre os entes federados, embora ainda seja necessário avançar nas condições estruturais, sobretudo, naquelas que tocam diretamente às condições de frequência e aproveitamento do curso.

Pela análise dos discursos das profissionais em formação pudemos constatar que para elas a práxis é fundamental para a constituição da docência na educação infantil, colocando em xeque a visão de que as profissionais buscam receituários e modelos prontos para a sua prática pedagógica e, nessa perspectiva, um curso latu senso torna-se um espaço privilegiado para tal aprofundamento, já que o estudo e a problematização das realidades de trabalho tornam-se pontos chave de todo o processo de formação continuada.

No que toca à permanência da Política Nacional de Formação, é urgente a necessidade de um debate mais profundo sobre a efetiva articulação entre os Municípios, as Universidades, o Governo Federal e demais instâncias envolvidas nos processos de aperfeiçoamento das profissionais. Este debate precisa levar em conta que um curso de especialização cumprirá o seu papel a medida que permite a problematização da realidade, o estudo aprofundado sobre a temática que propõe - nesse caso a docência na educação infantil - e temas afins, bem como o desenvolvimento da experiência de pesquisa (ainda que de forma exploratória, dada a temporalidade do curso).

Nas vozes das profissionais aparece a necessidade da continuidade da formação, mediante o fortalecimento de processos de formação continuada. Assim, fica o desafio de se avançar na Política de Formação no sentido de acentuar contornos que sejam próprios dos contextos de atuação das profissionais e que, mediante a colaboração efetiva entre os entes federados, se crie condições para a estruturação dos processos de formação de forma contínua e contextualizada, ou seja, em serviço, garantindo as condições de frequência e permanência no curso.

\section{Referências}

AMBROSETTI, N. B.; ALMEIDA, P. C. A. A constituição da profissionalidade docente: tornar-se professora de Educação Infantil. In: 30 Reunião Anual da ANPED. Caxambu/MG, 2007.

BONDIOLI, A. Riflettere sul contesto e le pratiche educative: un modello di evaluation formativa. In: BONDIOLI, A. Culture dell'infanzia. Roma: Edizioni Junior, 2004.

BRASIL. Decreto Presidencial $n^{\circ}$ 6.755, de 29 de janeiro de 2009. Política Nacional de Formação de Profissionais do Magistério da Educação Básica. Diário Oficial da União,Brasília/DF, 30 de jan. de 2009a.

Lei $n^{\circ}$ 9.394, de 23 de dezembro de 1996. Lei deDiretrizes e Bases da Educação Nacional. Diário Oficial da União, Brasília/DF, 23 de dez. de 1996.

Ministério da Educação. O Plano de Desenvolvimento da Educação. Razões, Princípios e Programas. Brasília/DF: MEC, 2007.

Ministério da Educação. Conselho Nacional de Educação. Câmara de Educação Básica. Resolução

$n^{\circ}$ 5, de 17 de setembro de 2009. Fixa as Diretrizes Curriculares Nacionais para a Educação Infantil. Brasília/DF: MEC, 2009b.

Ministério da Educação. Conselho Nacional de Educação. Câmara de Educação Básica. Parecer CNE/CEB $n^{\circ}$ 20, de 2009. Revisão das Diretrizes Curriculares Nacionais para a Educação Infantil. Brasília/DF: MEC, 2009C.

FAIRCLOUGHT, N. Discurso e Mudança Social. Brasília: Editora UnB, 2001.

FREITAS, H. C. L. Formação inicial e continuada: a prioridade ainda postergada. In: OLIVEIRA, D. A.; VIEIRA, L. F. Trabalho na Educação Básica: a condição docentes em sete estados brasileiros. Belo Horizonte: Fino Traço, 2012, p. 91-129.

GHEDIN, E. Professor reflexivo: da alienação da técnica à autonomia da crítica. In: PIMENTA, S. G. e GHEDIN, E. (Orgs.). Professor reflexivo no Brasil: gênese e crítica de um conceito. São Paulo: Cortez, 2002, pp. 129-149. 
NÓVOA, A. Formação de professores e profissão docente. In: NÓVOA, A. (Coord.). Os professores e a sua formação. Lisboa: Dom Quixote, 1992. pp. 13-33

SANTOS, E. A. S. A formação continuada na educação infantil: avaliação e expectativas das profissionais da rede municipal de Florianópolis. Dissertação (Mestrado em Educação). Universidade Federal de Santa Catarina, Centro de Ciências da Educação. Florianópolis, 2014.

SAVIANI, D. História da Formação docente no Brasil: três momentos decisivos. Revista do Centro de Educação. Santa Maria, v.30, n.2, 2005, p. 11-26. 